\title{
Method of Group Decision Making for Production Planning of the Oil Refinery Plant
}

\author{
Shixaliyev Kerem Sefi, Vaqif.H. Səlimov
}

\begin{abstract}
This article is devoted to the problem of decision making under uncertainty. An aggregated approach is used that combines optimization and choice of a solution, which makes it possible to obtain a more realistic solution. The criteria in the vector optimization problem are: profit, product quality, employee satisfaction. To solve the optimization problem, 3 methods were used: "Goal programming", "Interactive", "FMOLP". The task of group decision making is implemented on the basis of the package FGDSS-CD (Fuzzy group Decision Support System).

Keywords: Uncertainty, group decision making, planning, oil refinery plant, fuzzy, goal programming, interactive, FMOLP
\end{abstract}

\section{INTRODUCTION}

The group decision making methods have been developed for solving semi structured and unstructured problems [1-6], so for problems with high level of uncertainty of information. Uncertainty can be related with imprecise of given data and with uncertainty of goals so when we have several contradictory objectives. These methods usually are used for problems where alternatives are presented in non numerical values. As rule the preferences of experts are expressed by linguistics terms. In systems are based on group decision making technology , the experts make decisions by evaluation of proposed alternatives. The evaluation process is based on the intuition, experience and special algorithm of achieving

General structure of group decision making is presented

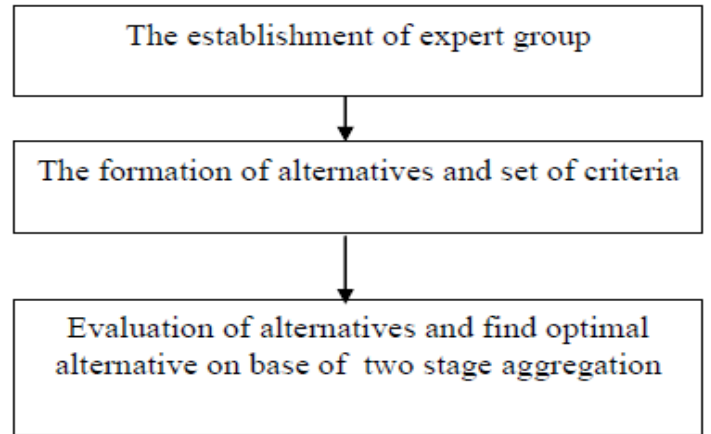

Fig. 1. General structure of group decision making

Manuscript received on 27 July 2021 | Revised Manuscript received on 04 August 2021 | Manuscript Accepted on 15 August 2021 | Manuscript published on 30 August 2021. * Correspondence Author

Shixaliyev Kerem Seyfi*, Professor, Department of Organic Substances and Technology of Macromolecular Compounds Azerbaijan State Oil and Industry University, Baku, Azerbaijan

Vaqif.H. Səlimov, Azerbaijan State Oil and Industry Universitety kerem_shixaliyev@mail.ru

(c) The Authors. Published by Lattice Science Publication (LSP). This is an open access article under the CC-BY-NC-ND license (http://creativecommons.org/licenses/by-nc-nd/4.0/) consensus.[7-9]. on Fig. 1.

If necessary, in general structure can be included the blocks for conversation pair wise values into absolute ones and normalization procedures. The most known methods are following:.

- ELECTRE method (Elimination and Choice Expressing

Reality);[10-12]/

- AHP method (Analytic hierarchy process);

- TOPSIS method (Technique for order Preference by similarity to ideal solution) and others;

The ELECTRE method was first method of classification alternatives. It was proposed by French scientist B.Rua. AHP method was proposed by American scientist T.Saati for analysis situation where application of mathematical methods is impossible. TOPSIS method use the approach where decision based on compromise of maximum distance from negative ideal and minimum distance from positive ideal decisions.

Consider the general scheme of group decision making. The group of experts $E_{k}{ }_{(\kappa=1, . . \mathrm{L})}$ are given. For any expert is assigned the weight coefficient $w_{k}(k=1, \ldots, L)$. This coefficient is reflects the trust level of expert. The set of criteria for evaluation of alternatives are given ( $j=1, \ldots, m$ )

For any criteria the weight is assigned $\left.v_{j} j=1, \ldots, m\right)$ Also the set of alternatives is determined $A_{i}, i=1, \ldots, n$

The process of determination of optimal alternative can be describe by two stage procedure . This process can be presented in pay off table form .

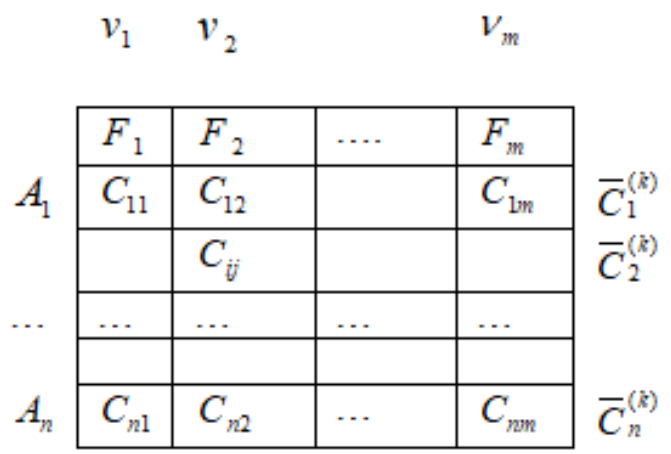

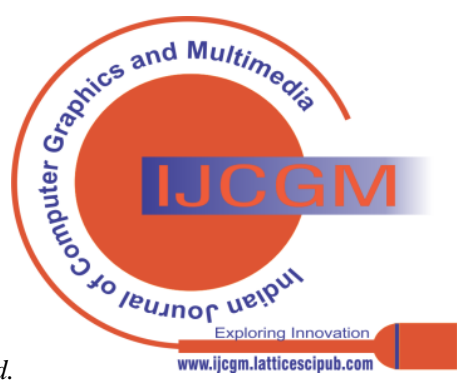


Here $\bar{C}_{i}^{(k)}$-is aggregative value of i-th alternative by $\mathbf{k - t h}$ expert, $C_{i j}$-value of i-th alternative by j-th criteria $C_{i j}$ are determine by expert by estimation. For any expert $E_{k}$ the payoff matrix is built. For any $\kappa$ alternative aggregative values $\bar{C}_{i}^{(k)}$

$\sum_{j=1}^{m} C_{i j} v_{j}=\bar{C}_{l}^{(k)} \quad k=\overline{1, l}, \quad i=\overline{1, n}$

In second stage the matrix of values by all experts is established. All operations are performed on base of fuzzy approach.

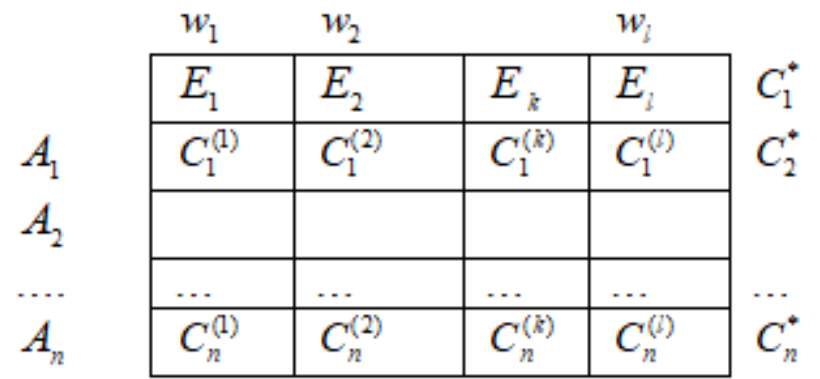

On base of weight coefficients of expert

$w_{k} \quad k=\overline{1, \ell}$ the aggregative value for any alternative are determined.

$\sum_{k=1}^{\ell} w_{k} C_{k}^{*}=C_{i}^{*}$

The process is finished by determination of optimal

alternative so aggregative solution by all experts $C_{i}^{*}$.

$i^{*}=\max C_{i}^{*}$

All group decision making methods are based on this general scheme , Fuzzy versions of this approach differs on usage of linguistic variables.

Consider the planning of oil refinery plant. The problem is present in multicriteria variant. Refinery process consists of two units: production and compound. (Fig.2)

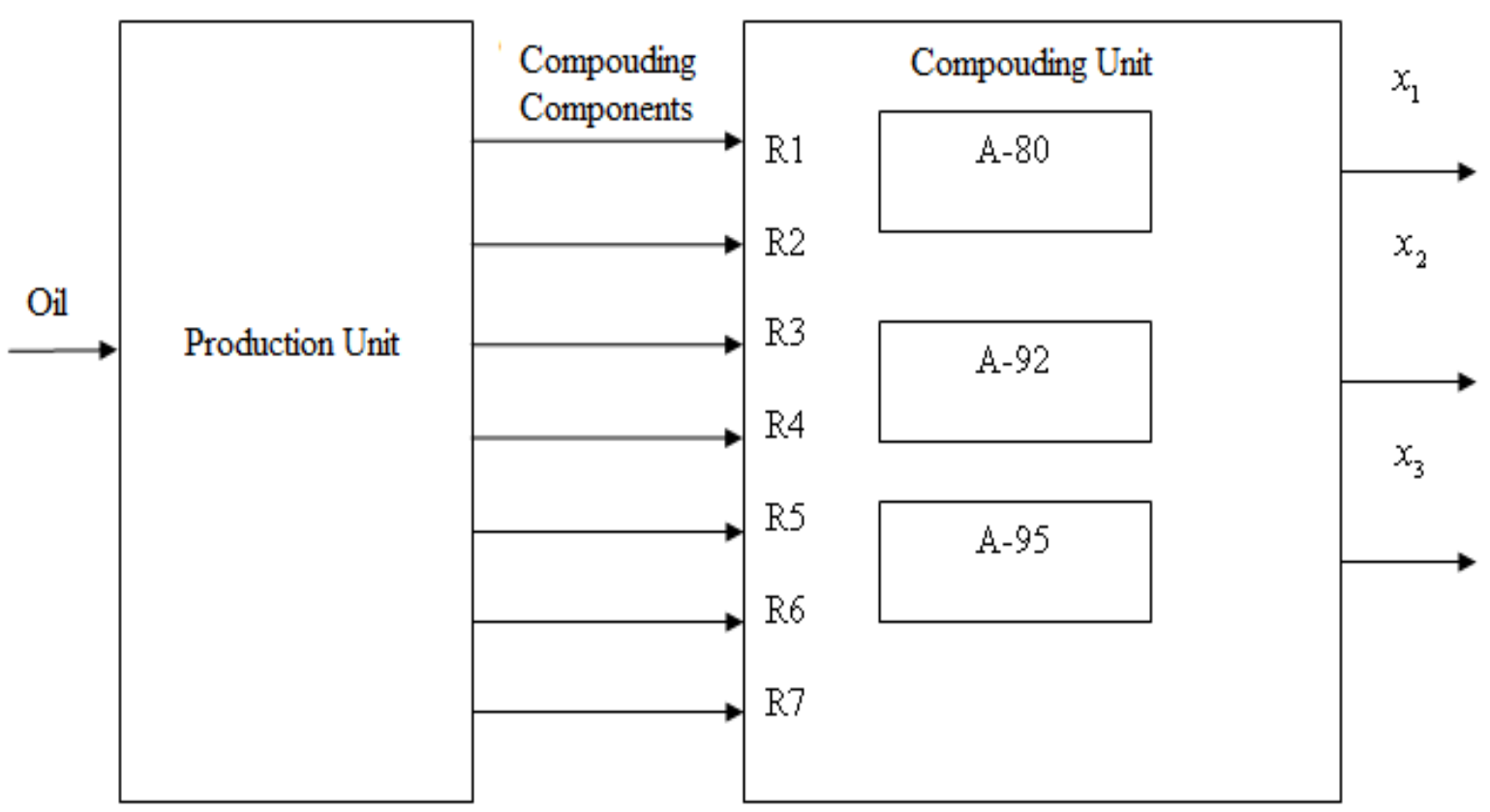

Fig. 2. The major units of oil refinery process

Production unit realize two stages oil refinery process. In the first stage is conducting of primary oil processing, in the next stage the catalytic cracking and coke processes are performing. In production unit are produced the fraction which are used needed for manufacturing car petrol.

\section{METHOD}

\section{The fuzzy planning problem statement}

In last years many scientists for planning problem use multicriteria problem where are used economical, social and ecology criteria. In this connects the fuzzy problem statement can be presented as following:

Fuzzy Goal function includes three functions : profit, product quality, worker satisfaction

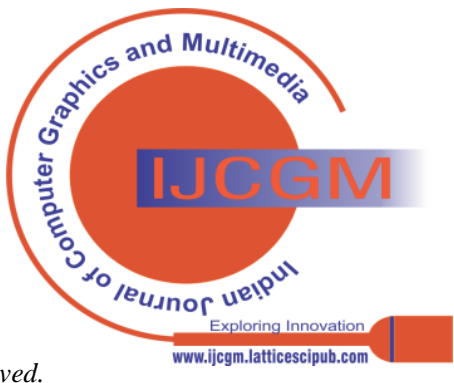




$$
\max \tilde{f}(x)=\max \left(\begin{array}{c}
\tilde{f}_{1}(x) \\
\tilde{f}_{2}(x) \\
\tilde{f}_{3}(x)
\end{array}\right)=\max \left(\begin{array}{l}
\tilde{c}_{11} x_{1}+\tilde{c}_{12} x_{2}+\tilde{c}_{13} x_{3} \\
\tilde{c}_{21} x_{1}+\tilde{c}_{22} x_{2}+\tilde{c}_{23} x_{3} \\
\tilde{c}_{31} x_{1}+\tilde{c}_{32} x_{2}+\tilde{c}_{33} x_{3}
\end{array}\right)=\max \left(\begin{array}{l}
28 \tilde{8} x_{1}+2 \tilde{9} 0 x_{2}+3 \tilde{0} 0 x_{3} \\
\tilde{8} x_{1}+\tilde{5} x_{2}+\tilde{3} x_{3} \\
\tilde{4} x_{1}+\tilde{8} x_{2}+\tilde{6} x_{3}
\end{array}\right)
$$

fuzzy constraints:

\section{Resource constraints :}

HK-85 fraction: $\tilde{a}_{11} x_{1}+\tilde{a}_{12} x_{2}+\tilde{a}_{13} x_{3}=0.2 \tilde{2} 89 x_{1}+0.0 \tilde{1} 028 x_{2} \leq b_{1}=27611.9$

Stabile platformate

$\tilde{a}_{21} x_{1}+\tilde{a}_{22} x_{2}+\tilde{a}_{23} x_{3}=0.0 \tilde{6} 91 x_{1}+0.3 \tilde{4} 94 x_{2}+0.7 \tilde{8} 57 x_{3} \leq b_{2}=38 \tilde{6} 214$

Coker gasoline: $\tilde{a}_{31} x_{1}+\tilde{a}_{32} x_{2}+\tilde{a}_{33} x_{3}=0.08 \tilde{4} 6591 x_{1} \leq \tilde{b}_{3}=69 \tilde{2} 5.4$

high-octane component:

$$
\tilde{a}_{41} x_{1}+\tilde{a}_{42} x_{2}+\tilde{a}_{43} x_{3}=0.4 \tilde{9} 01 x_{1}+0 . \tilde{6} 402 x_{2}+0.2 \tilde{1} 42 x_{3} \leq \tilde{b}_{4}=61 \tilde{4} 955
$$

Virgin gasoline: $\tilde{a}_{51} x_{1}+\tilde{a}_{52} x_{2}+\tilde{a}_{53} x_{3}=0 . \tilde{0} 4718 x_{1} \leq \tilde{b}_{5}=38 \tilde{5} 8$

HK-85-180 fraction: $\tilde{a}_{61} x_{1}+\tilde{a}_{62} x_{2}+\tilde{a}_{63} x_{3}=0.0 \tilde{1} 289 x_{1} \leq \tilde{b}_{6}=10 \tilde{5} 4.40$

Hydro treated gasoline: $\tilde{a}_{71} x_{1}+\tilde{a}_{72} x_{2}+\tilde{a}_{73} x_{3}=0 . \tilde{0} 671 x_{1} \leq \tilde{b}_{7}=54 \tilde{8} 7.8$

\section{Plan constraints:}

Production of gasoline A-80: $\tilde{a}_{81} x_{1}+\tilde{a}_{82} x_{2}+\tilde{a}_{83} x_{3}=\tilde{1} x_{1} \geq \tilde{b}_{8}=20 \tilde{0} 0$

Production of gasoline A-92: $\tilde{a}_{91} x_{1}+\tilde{a}_{92} x_{2}+\tilde{a}_{93} x_{3}=\tilde{1} x_{2} \geq \tilde{b}_{9}=20 \tilde{0} 0$

Production of gasoline A-95: $\tilde{a}_{101} x_{1}+\tilde{a}_{102} x_{2}+\tilde{a}_{103} x_{3}=\tilde{1} x_{3} \geq \tilde{b}_{10}=20 \tilde{00} 0$

Products quality constraints :

$$
\begin{gathered}
\tilde{a}_{111} x_{1}+\tilde{a}_{112} x_{2}+\tilde{a}_{113} x_{3}=0.27 \tilde{7} 569 x_{1} \geq \tilde{b}_{11}=0 \\
\tilde{a}_{121} x_{1}+\tilde{a}_{122} x_{2}+\tilde{a}_{123} x_{3}=0.07 \tilde{3} 72 x_{2} \geq \tilde{b}_{12}=0 \\
\tilde{a}_{131} x_{1}+\tilde{a}_{132} x_{2}+\tilde{a}_{133} x_{3}=0.0 \tilde{0} 62 x_{3} \geq \tilde{b}_{13}=0
\end{gathered}
$$

Balance constraints : $\tilde{a}_{141} x_{1}+\tilde{a}_{142} x_{2}+\tilde{a}_{143} x_{3}=\tilde{1} x_{1}+\tilde{1} x_{2}+1 \tilde{x}_{3} \leq \tilde{b}_{14}=104 \tilde{6} 107.1$

Where $\mathrm{x}_{1}$-amount of gasoline $\mathrm{A}-80, \mathrm{x}_{2}$ - amount of gasoline A-92, $x_{3}$ - amount of gasoline A-96.Coefficiets of objective functions and constraints are presented by fuzzy triangle numbers (LR) type.

$$
\mu_{\tilde{\mathrm{a}}}(\mathrm{x})=\left\{\begin{array}{l}
0, \quad \mathrm{x}<\mathrm{a} \text { или } c<x \\
(x-a) /(b-a), \quad a \leq \mathrm{x}<\mathrm{b} \\
1, \quad x=b \\
(c-x) /(c-b), \quad b<x \leq c
\end{array}\right.
$$

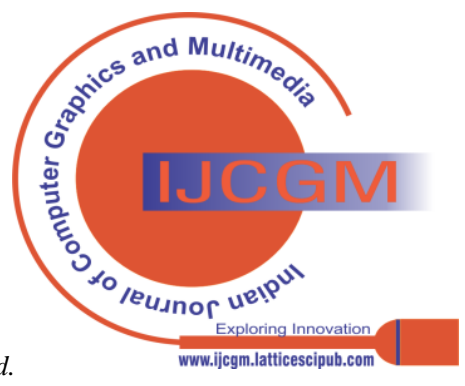




\section{RESULTS}

This problem have been solved by three methods of multicriteria optimization : FMOLP, GOAL programming, Interactive method.

Consider the one scheme of group decision making to problem to find consensus of decision which have been achieved by three different methods. As results of solving oil refinery planning problem on base of multicriteria model with 3 criteria-profit, quality and worker satisfaction by three different methods, ("Goal programming ","Interactive", "FMOLP") are presented in Table 1.

Table 1.

\begin{tabular}{|c|c|c|}
\hline "Goal programming" method & "Interactive" method & "FMOLP" method \\
\hline$X[1]=42079,3098$ & $\mathrm{X}[1]=48013.8179$ & $X[1]=42117.8841$ \\
\hline$X[2]=897406,6352$ & $X[2]=901917.0926$ & $X[2]=898834.0329$ \\
\hline$X[3]=88777.4486$ & $X[3]=65434.6646$ & $X[3]=88139.2835$ \\
\hline$\tilde{f}_{1}(x)=2900 \tilde{0} 00000$ & $\tilde{f}_{1}(x)=295014335.7861$ & $\tilde{f}_{1}(x)=2992333636.19$ \\
\hline$\tilde{f}_{2}(x)=5090000$ & $\underset{\sim}{f_{2}}(x)=5090000$ & $\tilde{\sim}_{2}(x)=509 \tilde{\sim} 531.98$ \\
\hline$\tilde{f}_{3}(x)=7880 \tilde{2} 235$ & $f_{3}(x)=78000000$ & $\tilde{f}_{3}(x)=7887979.81$ \\
\hline
\end{tabular}

These solutions are considered as alternatives $A_{1}, A_{2}, A_{3}$ and also group of experts $E_{1}, E_{2}, E_{3}$ are presented for find final decision of problem. For solving this problem is used software package FGDSS-CD(Fuzzy group Decision Support System). In first stage are determined weight coefficients of any expert and list of criteria (Fig. 3.)

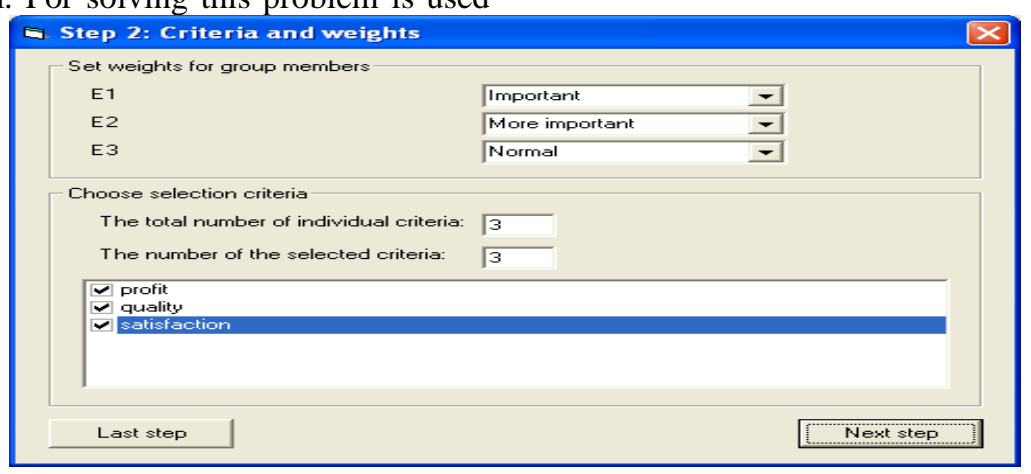

Fig.3. The determination weight coefficients of experts and forming of criteria set.

In next step any expert enter the pairwise matrix of own preferences to the criteria and evaluate all alternatives . All operations are realized in the fuzzy formalism ( Fig. 4).

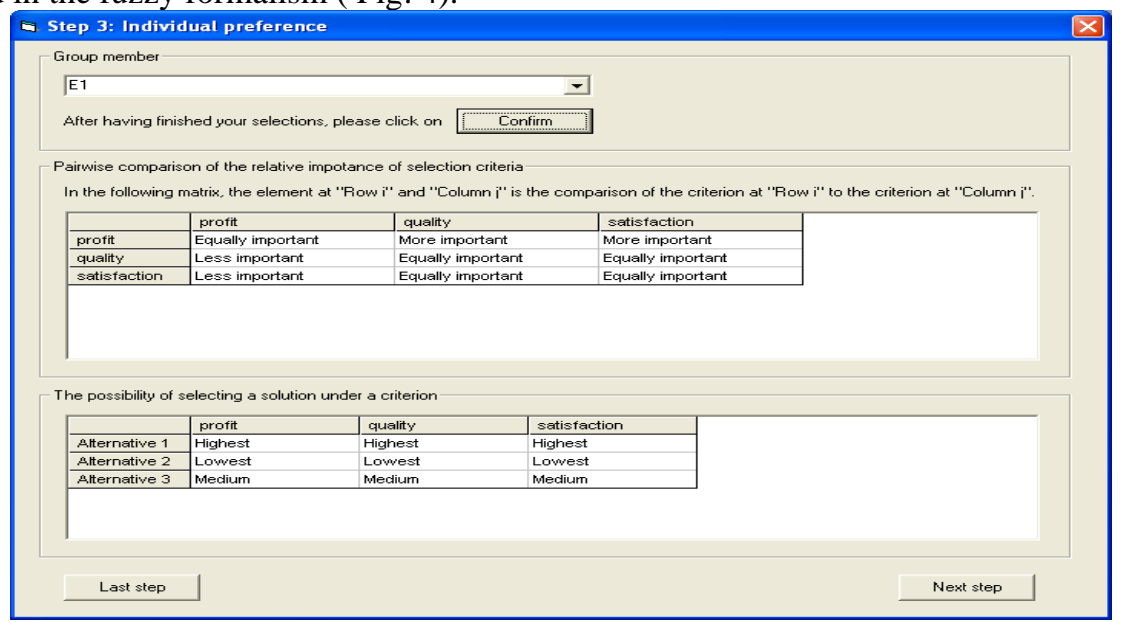

Fig. 4. Entering the pairwise preferences matrix and alternative's evaluation for expert $E_{1}$.

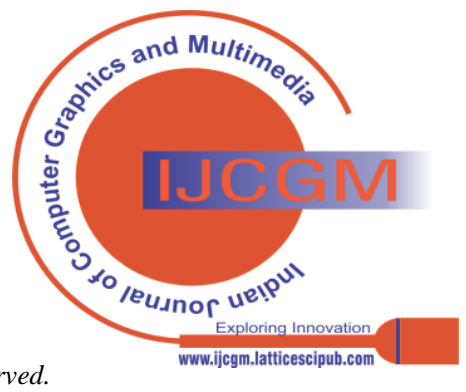


In next step was performed aggregation procedure by experts.(Fig.5.)

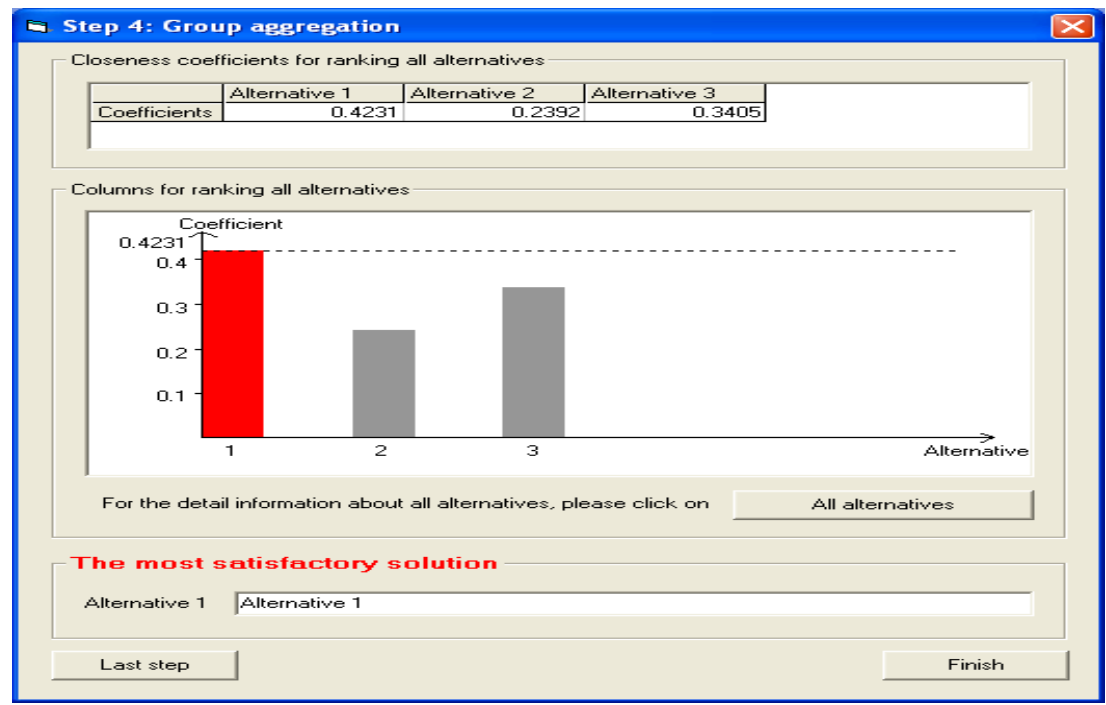

Fig. 5. The achievement of the final decision

As result of twice aggregation we have final decision ( first alternative was selected).

\section{CONCLUSION}

İn this paper the method of group decision-making is developed for a solving problem of planning of process of oil refinery under uncertainty. From three results obtained by three decision groups wich applied various approaches, the problem of choosing an optimal solution was solved.
12. Turaev ER, Beknazarov HS, Akhmedov UK, Dzhalilov AT// Interfacial interactions of three-phase polypropylene composite materials./Universum.Technical sciences./- 2018-№12.-p.57

\section{REFERENCES}

1. Leyva-Lopez, J.C., and E. Fernandez-González, (2003), “A new method for group decision support based on ELECTRE III methodology," European Journal of Operational Research, Vol. 148, pp. 14-27. [CrossRef]

2. Saaty T.L., Fundamentals of Decision Making and Priority Theory with the AHP, RWS Publications, Pittsburgh, PA, U.S.A., (1994).

3. Jie Lu, Guangquan Zhang Da Ruan, Fendjie Wu.Multi-objective group decision Making. Imperial College Press, London, 2007, 390.

4. Filip Andonov. An Interactive method for Group Decision Making. Problems of Engineering Cybernetics and Robotics, Bulgarian Academy of Sciences, Sofia, 2006. 57, pp. 3-7,

5. Chung-Hsing Yeh, Yu-Hern Chang. Modeling subjective evaluation for fuzzy group multicriteria decision making. European Journal of Operational Research, Volume 194, Issue 2, 16 April 2009, Pages 464-473 [CrossRef]

6. C.T.Chen. "Extensions of the TOPSIS for group decision-making under fuzzy environment," Fuzzy set anf Syatems., vol. 114. no. I. pp. 1-9, Aug. 2000. [CrossRef]

7. Base of technology processing of plastic mass. Text-book for high schools/S.V.Vlasov, M. "Chemistry", 2004, 600p.

8. Amirov Fariz.Shixaliyev Kerem. Properties of Linear Low Density Polyethylene. International Journal of Innovative Technology and Exploring Engineering (IJITEE). Volume-9 Issue-9, July 2020.pp. 348-352 ISSN: 2278-3075. SCOPUShttps: //www.ijitee.org/download/volume-9-issue-3/

9. Kerem Shixaliyev. Paint and Varnish Materials Based on Epoxy Novolac oliqomers Jour of Adv Research in Dynamical \& Control Systems. Vol. 12, Special Issue-02, 2020.pp351-358

10. Kerem ShixaliyexSefi..DETERMINATION OF COMPATIBILITY OF POLYMER SYSTEMS, SKEP, PU, KhKPE and CH EMICAL FEATURES OF THEIR MIXTURES. Jour of Adv Research in Dynamical \& Control Systems. Vol. 12, Special Issue-02, 2020.pp359-370

11. Ermilova EA, Sizova AA, Ilyicheva NN, Pleshakov DV // Study of thermodynamic compatibility of a three-component mixture of nitramines with a copolymer of methyl methacrylate and methacrylic acid technology / Chemical successes. .-2014 - №2.-p.65-67.

\section{AUTHORS PROFILE}

Shixaliyev Kerem Seyfi, Doctor of Technical Sciences Professor-Academician of the European Academy of Natural Sciences Professor, Department of Organic Substances and Technology of Macromolecular Compounds Azerbaijan State Oil and Industry University, Baku, Azerbaijan

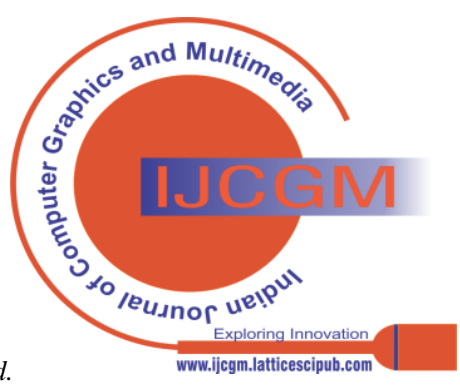

